BMJ Open

Sport \&

Exercise

Medicine

\title{
Concussion knowledge and experience among Welsh amateur rugby union coaches and referees
}

\author{
Steffan Arthur Griffin, ${ }^{1}$ Craig Ranson, ${ }^{2}$ Isabel Moore, ${ }^{2}$ Prabhat Mathema ${ }^{3}$
}

To cite: Griffin SA,

Ranson C, Moore I, et al. Concussion knowledge and experience among Welsh amateur rugby union coaches and referees. BMJ Open Sport Exerc Med 2017:3:e000174.

doi:10.1136/bmjsem-2016000174

- Additional material is published online only. To view please visit the journal online (http://dx.doi.org/ 10.1136/bmjsem-2016000174).

Accepted 31 January 2017

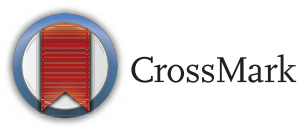

${ }^{1}$ College of Medical and Dental Sciences, University of Birmingham, Birmingham, UK

${ }^{2}$ Sports injury Research Group, Cardiff School of Sport, Cardiff Metropolitan University, Cardiff, UK ${ }^{3}$ Medical Services Department, Welsh Rugby Union, Cardiff, UK

Correspondence to Dr Steffan Arthur Griffin; steffangriffin@gmail.com

\section{ABSTRACT}

Background Rugby union is a collision sport where participants are at high risk of sustaining a concussion. In settings where there is little qualified medical supervision, certain stakeholders (eg, coaches and officials) should possess sufficient knowledge in regard to the recognition and management of concussion. Aim The aim of this study was to assess the knowledge and experience of various aspects of concussion among coaches and referees involved in Welsh amateur rugby union.

Methods A questionnaire was distributed to 1843 coaches and 420 referees.

Results A total of 333 coaches and 283 referees completed the questionnaire (18\% and $68 \%$ response rates, respectively). Participants exhibited greater knowledge of concussion symptom recognition relative to knowledge of both the consequences of concussion and associated return-to-play protocols, both of which could be considered poor. There were no differences in knowledge levels between coaches and referees or between participants with or without a history of concussion. Two-thirds of participants incorrectly believed that headgear could prevent concussion, and nearly $30 \%$ of coaches reported having witnessed other coaches allowing a potentially concussed player to continue playing.

Conclusions Identification of several misconceptions indicates that concussion management within Welsh amateur rugby union needs to be improved, warranting a multi-faceted educational intervention.

\section{INTRODUCTION}

Rugby union is a collision sport played by over six million participants in over 120 countries, ${ }^{1}$ with a concussion rate among the highest of any football code. ${ }^{2}$ Concussion refers to a traumatically induced transient disturbance of brain function, caused by complex pathophysiological processes, ${ }^{3}$ and represents approximately $6 \%-8 \%$ of all injuries in rugby union. ${ }^{4-9}$ It is also one of the most common match injuries among professional players ${ }^{9} 10$ with its incidence steadily increasing over the last decade. ${ }^{3} 11$ It is believed that part of this increase is attributable to more accurate

\section{What are the new findings}

- Coaches and referees involved in Welsh amateur rugby union have good knowledge of the signs and symptoms of concussion.

- Misconceptions are present in regard to the prevention and consequences of concussion, as well as in regard to return to play guidelines.

- These results may indicate that concussion management within Welsh amateur rugby union needs to be improved, through a proposed multi-faceted educational intervention.

reporting, associated with improved concussion education and awareness, ${ }^{3}$ although athlete under-reporting remains prevalent. $^{12} 13$

While there is ongoing research into the prospective use of neuroimaging, electrophysiological tests and clinical biomarkers of concussion, there is insufficient evidence to justify their use in clinical practice. ${ }^{14-17}$ As such, diagnosis currently hinges on the subjective identification of the clinical signs and symptoms (table 1). Approximately $80 \%-90 \%$ of the most common signs and symptoms of concussion usually resolve within 7-10 days of the initial injury. ${ }^{3} 18-20$

Concussion management guidelines stress the importance of immediately removing any potentially concussed athlete from the playing or training field. ${ }^{3} 17$ These guidelines are based on studies showing potentially serious short-term risks associated with continuing to participate in the activity following a concussive event. ${ }^{5}$ These risks include the potentially fatal 'secondimpact syndrome' and an increased likelihood of further head injury and injuries to other parts of the body. ${ }^{21-23}$ In the long term, other pathologies that have proposed links to concussion include chronic traumatic encephalopathy, ${ }^{3}$ depression, ${ }^{24}$ mild cognitive impairment and selfreported memory impairments. ${ }^{25}$ However, 


\begin{tabular}{|c|c|c|}
\hline & Signs & Symptoms \\
\hline \multirow[t]{6}{*}{ Physical } & Vomiting & Headache \\
\hline & Balance problems & Nausea \\
\hline & Sensitivity to light & Dizziness \\
\hline & Sensitivity to noise & $\begin{array}{l}\text { Visual } \\
\text { problems }\end{array}$ \\
\hline & Dazed & Fatigue \\
\hline & Stunned & $\begin{array}{l}\text { Numbness/ } \\
\text { tingling }\end{array}$ \\
\hline \multirow[t]{4}{*}{ Cognitive } & $\begin{array}{l}\text { Forgetful of recent } \\
\text { information and } \\
\text { conversations }\end{array}$ & $\begin{array}{l}\text { Difficulty } \\
\text { concentrating }\end{array}$ \\
\hline & $\begin{array}{l}\text { Confused about recent } \\
\text { events }\end{array}$ & $\begin{array}{l}\text { Difficulty } \\
\text { remembering }\end{array}$ \\
\hline & $\begin{array}{l}\text { Answers questions } \\
\text { slowly }\end{array}$ & $\begin{array}{l}\text { Feeling } \\
\text { mentally } \\
\text { 'foggy' }\end{array}$ \\
\hline & Repeats questions & $\begin{array}{l}\text { Feeling } \\
\text { slowed down }\end{array}$ \\
\hline \multirow[t]{2}{*}{ Sleep related } & Sleeping more than usual & $\begin{array}{l}\text { Difficulty } \\
\text { falling asleep }\end{array}$ \\
\hline & Sleeping less than usual & Drowsiness \\
\hline \multirow[t]{4}{*}{ Emotional } & - & Irritable \\
\hline & & Sadness \\
\hline & & $\begin{array}{l}\text { More } \\
\text { emotional }\end{array}$ \\
\hline & & Nervousness \\
\hline
\end{tabular}

Adapted from Harmon et al. ${ }^{3}$

further research is required before firm links can be drawn.

The need to immediately remove any potentially concussed athlete from the athletic setting is advised within the 2012 international consensus statement on concussion in sport, ${ }^{17}$ with further recent guidance from World Rugby stating that 'any abnormal assessment confirms a concussion diagnosis unless the treating doctors provides clinical confirmation that the abnormal findings are not related to a concussion'. ${ }^{26}$ In regard to the return-to-play process following a concussion, the guidelines for Welsh amateur rugby union players are based on the World Rugby and international consensus recommendations. ${ }^{27}$ The protocol advocates an initial relative rest period of 14 days following the resolution of symptoms, before commencing a graduated return-to-play process. ${ }^{27}$.

Knowledge regarding the recognition and management of concussion has been investigated in a range of lay stakeholders including athletes, coaches and parents. ${ }^{28-33}$ In settings where there is little to no qualified medical supervision, such stakeholders have an important role to play in player welfare and should possess sufficient knowledge in regard to the recognition and management of concussion. ${ }^{29} 34$

Coaches in multiple sports have demonstrated concussion knowledge deficiencies. ${ }^{31}{ }^{35-37}$ This is a worrying finding given that up to half of high school rugby union players report that they would consult their coach for information relating to concussion ${ }^{33}$ and a similar proportion of age-grade rugby union players being more likely to report concussion to their coach as opposed to a physiotherapist or doctor. $^{28}$ Additionally, despite satisfactory levels of knowledge and understanding of concussion within a cohort of professional rugby union coaches, ${ }^{29}$ there is a high prevalence of concussion-related misconceptions among elite rugby union coaches ${ }^{38}$ whose results were similar to those among community-level Australian football and rugby league coaches and sports trainers. ${ }^{39}$

Only two studies have researched referees' knowledge of concussion, one of which involved a cohort of only three rugby league referees, ${ }^{31}$ therefore not allowing meaningful conclusions to be drawn. The other ${ }^{38}$ reported a knowledge gap in relation to the symptoms and consequences of concussion among elite-level rugby union referees. No evidence exists regarding the levels of concussion-related knowledge among amateur rugby union referees. This cohort is of high importance given their ability to order an injured player from the playing area, with or without the advice of medically qualified individuals. ${ }^{40}$

With the incidence of concussion increasing in tandem with the reporting of potentially serious short and long-term consequences, ${ }^{3}{ }^{11}$ the aim of this study was to assess the knowledge and experience of various aspects of concussion among coaches and referees involved in Welsh amateur rugby union.

\section{METHODOLOGY}

The design of the questionnaire involved modifying a similar paper-based questionnaire previously developed for a concussion knowledge and experience audit within elite rugby union stakeholders in Wales. ${ }^{38}$ The questionnaire was developed using the Qualtrics software program (Qualtrics, Provo, Utah) and content was based on World Rugby and the Welsh Rugby Union $(\mathrm{WRU})^{27}$ guidelines, the 2012 consensus statement on concussion in sport, ${ }^{17}$ the American Medical Society for Sports Medicine position statement and a questionnaire used to assess the concussion knowledge among coaches and referees involved in elite WRU. ${ }^{38}$ Although not fully validated, verification of the questionnaire flow and structure was achieved by piloting the questionnaire among six coaches from two amateur rugby union clubs as well as a cohort of 30 randomly selected referees. 
A

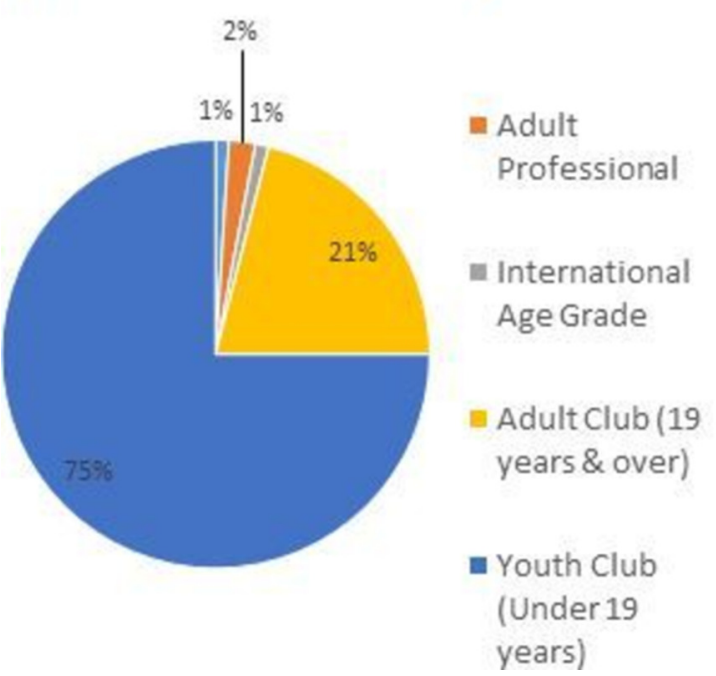

B

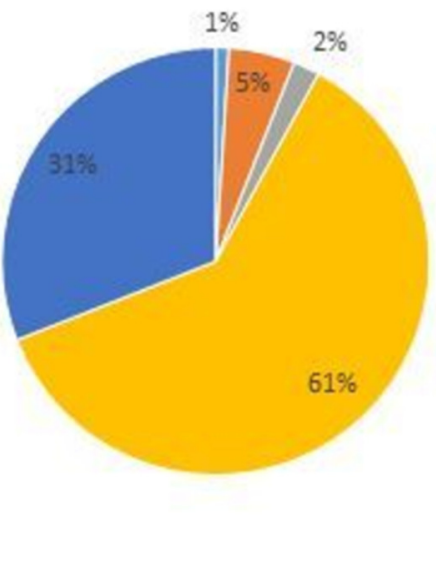

- International

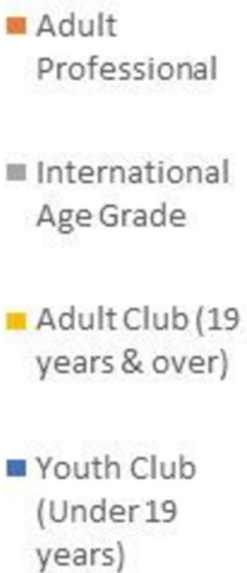

Figure 1 (A) The level at which coaches reported contributing to rugby union in Wales. (B) The level at which referees reported officiating rugby union matches in Wales.

Each questionnaire (online supplementary files 1 and 2) was tailored to be specifically relevant to coaches and referees, although questions relating to symptom recognition, consequences of concussion and return to play were kept identical to enable comparison between groups. To assess concussion symptom recognition, a list of potential physical, cognitive and emotional symptoms was devised, which included the 10 most common signs and symptoms of concussion along with 10 'distractor' signs and symptoms. An additional question ('Do you have to be 'knocked out' to be concussed?') was included in this section. All items and questions were scored on dichotomous 'yes' or 'no' scales, with correct answers given a score of 1, resulting in a maximal concussion symptom recognition score of 21. Knowledge of the consequences of concussion included three multiple-choice questions relating to the short-term risks, long-term consequences and prevention of concussion, with a maximal possible score of 16. Questions relating to return to play were used to assess knowledge of the current WRU graduated return-to-play protocol. The maximal return-toplay knowledge score was 6. As all questions were formatted as multiple-choice questions, equal weighting was given to each question, as per the work of Mathema and colleagues. ${ }^{38}$

Data collection was achieved by emailing the link to the questionnaire to all known qualified rugby union coaches $(n=1843)$ contained in email databases held by the WRU coaching development department. Referees were contacted through the WRU's National Match Officials Manager, who included the hyperlink in an email to all eligible participants $(n=420)$. Reminder emails were sent at 14-day intervals over a 4-week period.
Ethical approval was granted by Cardiff School of Sport's research ethics committee. The questionnaire was categorised as 'confidential' rather than anonymous as participants were requested to provide their personal postcode for future demographic analyses. The study information sheet and consent form were integrated into the first two pages of the electronic questionnaires. Participants who did not consent were not able to proceed and complete any part of the questionnaire.

Descriptive data (mean, 95\% CI, median, IQR, absolute numbers, percentages) are presented where appropriate. Due to the non-normality of the numerical data, Mann-Whitney $\mathrm{U}$ tests were used to assess significant differences between the scores of coaches and referees. For categorical data, Pearson $\chi^{2}$ was calculated. All analysis was conducted within SPSS V.20 (Statistical Package for Social Sciences), with significance set at $\mathrm{p} \leq 0.05$.

\section{RESULTS}

A total of 621 questionnaires were returned (337 coaches and 284 referees), providing response rates of $19 \%$ for coaches and $68 \%$ for referees. Those who reported that they had not heard of concussion (four coaches and one referee) answered only the questions relating to demographics and concussion education. As such, 333 coaches and 283 were included in the analysis. Over $50 \%$ of these participants reported that they had sustained a concussion while playing rugby. The level at which participants reported contributing to Welsh amateur rugby union in a coaching or refereeing capacity is demonstrated in figure 1.

The mean concussion symptom recognition score was 18.6 out of 21 (95\% CI 18.4 to 18.7). There was no difference in symptom recognition score between 


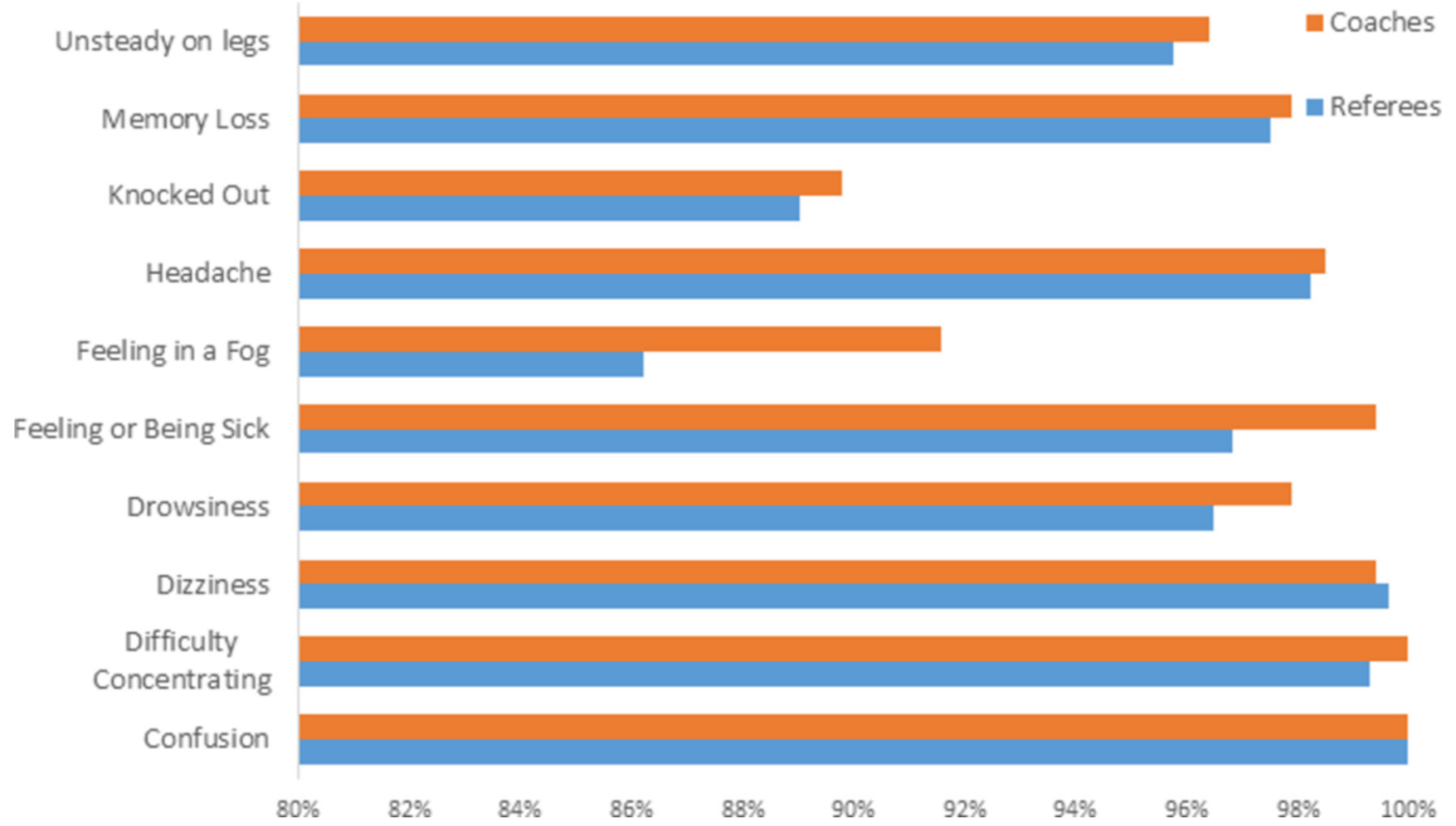

Figure 2 Proportion of amateur Welsh rugby union coaches and referees who correctly identified the 'true' signs and symptoms of concussion.

coaches and referees $(\mathrm{U}=46930, \mathrm{p}=0.930)$, between participants with or without a history of concussion $(\mathrm{U}=44825, \mathrm{p}=0.250)$ or those who had or had not received concussion education $(\mathrm{U}=51571.5, \mathrm{p}=0.052)$. A total of $95 \%$ of participants correctly identified that loss of consciousness was not required in order for a player to be diagnosed with concussion. A graphical representation of the proportion of coaches and referees who correctly identified each sign and symptom of concussion is provided in figure 2.

The mean consequences of concussion knowledge score was 11.7 out of 16 (95\% CI 11.5 to 11.8$)$, with no difference between coaches and referees $(\mathrm{U}=45030$, $\mathrm{p}=0.336)$ or between those with or without a history of concussion $(\mathrm{U}=41080, \mathrm{p}=0.474)$. Those who had previously received some form of concussion education scored higher (13.9) than those who had not (13.2) $(\mathrm{U}=55505, \mathrm{p}<0.001)$. The short-term risk least likely to be identified was reduced performance $(62 \%)$ while early-onset Parkinson's disease was the long-term consequence least correctly identified (43\%). Headguards were incorrectly reported as protective against concussion by $67 \%$ of participants, while $71 \%$ incorrectly reported that protective equipment offered protection against concussion.

The mean return-to-play knowledge score was 1 out of 6 (95\% CI 0.9 to 1.1), with no difference between coaches and referees $(\mathrm{U}=44673, \mathrm{p}=0.229)$ or between those with or without a history of concussion $(\mathrm{U}=42061, \mathrm{p}=0.807)$. Those who had previously received some form of concussion education scored higher (1.3) than those who had not (0.7) $(\mathrm{U}=56934$, $\mathrm{p}<0.001)$.
Fifty-seven coaches (17\%) reported having been asked to provide concussion advice. Over 92\% of coaches correctly responded that a subsequently asymptomatic player who had been knocked out or had been showing signs of concussion should not be allowed to remain on the field. Nearly $95 \%$ reported that they would immediately remove a potentially concussed player from the field of play, with $95 \%$ stating having never allowed a potentially concussed player to continue playing. These correct actions contrast with the finding that over a quarter $(n=97)$ of participants responded as having seen other coaching staff allow potentially concussed players to continue playing.

Nineteen per cent of referees reported having been asked to provide concussion advice. Over 95\% of referees correctly reported that a subsequently asymptomatic player who had been knocked out or had been showing signs of concussion should not be allowed to remain on the field. Nearly $40 \%$ reported having seen a coach pressure a potentially concussed player to continue playing, and $28 \%$ had seen a coach pressure medical staff into allowing a potentially concussed player to continue playing.

Both groups reported a preference for future education via integration into existing training courses as well as via the WRU website.

\section{DISCUSSION}

This is the first article to report the concussion knowledge and experience of coaches and referees within amateur rugby union. While there appears to be a sound level of knowledge of concussion, some prevalent misconceptions remain. These include belief in 
the preventative effectiveness of head guards or protective equipment and a relative paucity of knowledge regarding return-to-play guidelines. Understanding these knowledge gaps in concussion recognition and management will inform ongoing key stakeholder education programmes within the sport.

The concussion symptom recognition scores demonstrated that both coaches and referees possess a satisfactory level of knowledge in this area. Encouragingly, both groups were better at identifying known signs and symptoms than 'distractors', meaning both coaches and referees may be more proficient in identifying concussion than ruling it out. The mean symptom recognition score was also higher in this study than has been reported among other coaching cohorts, ${ }^{31}$ 37-39 suggesting that recent educational strategies $^{27}{ }^{41}$ may have succeeded in enabling certain stakeholders to recognise the signs and symptoms of concussion. This may also underlie the encouraging finding that only a small minority $(5 \%)$ incorrectly responded that a loss of consciousness was required to diagnose concussion. However, this finding may not be representative of the entire population as only $19 \%$ of coaches completed the survey, and this sample may be more engaged in player welfare initiatives and also more knowledgeable than non-responders.

While the overall knowledge of the consequences of concussion can be considered satisfactory, with the exception of performance decrement following concussion, possible short-term risks were well identified. However, knowledge of some of the potential longterm consequences of concussion, such as early-onset cognitive and memory deficits, was poor. As such, addressing this knowledge gap may improve decision making with regards to removing potentially concussed players from the field of play. Of considerable concern is that the vast majority of participants reported that headgear and/or other protective equipment (eg, mouthguards and headguards) would protect against concussion. Education strategies need to specifically address this misconception, on the basis that there is a lack of evidence that suggests protective equipment will protect rugby union players against concussion. ${ }^{42-44}$

An average return-to-play knowledge score of only 1 (out of 6) warrants concern, due to the fact that approximately $20 \%$ of coaches and referees reported having been asked to provide concussion management advice. As such, there is a level of expectation that both groups should at least be able to confidently state the minimum time a player should have off full contact matches following a concussion. The return-to-play knowledge scores were lower relative to stakeholders involved in the elite level of the sport, ${ }^{38}$ suggesting that the return-to-play educational message is not reaching the amateur level and that further education is required.

Despite only $7 \%$ of coaches reporting that they would not immediately remove a potentially concussed player from the field of play, one of the key findings was that over a quarter of coaches had witnessed other coaches allowing a potentially concussed player to continue playing. This discrepancy between observed behaviour and self-reported behaviour could be attributable to a self-selection bias attributable to the study design, ${ }^{45}$ although this is unlikely due to the high prevalence of misconceptions. It is more likely that this finding is based on comparative optimism, ${ }^{46}$ with coaches subconsciously over-reporting personal 'good' practice in order to conform to the expected standard of care. ${ }^{46}$

47 This phenomenon may suggest that actual practice could be closer linked to observed practice; this is of particular importance as $75 \%$ of coaches reported coaching youths, a cohort at increased risk of both sustaining a concussion ${ }^{3}$ and associated catastrophic injury. ${ }^{48}$

The majority of referees $(85 \%)$ correctly identified that they have the ultimate say on whether a player remains on the pitch and $40 \%$ reported having seen coaches pressurising potentially concussed players to continue playing. This indicates that referees play an integral role in the optimal management of concussion. Educating referees on the consequences and management of concussion could theoretically improve the likelihood of referees intervening in these cases, though further research is required in this area, especially in regard to the relationship between knowledge and behaviour.

Both groups reported a preference for future education via integration into existing training courses as well as via the WRU website, something that is already being acted on by the governing body. ${ }^{49}$ Such a multidimensional approach to resource provision has been proven to educate and modulate coaches' perception of concussion as well as increase the likelihood of peerled informal education on the topic ${ }^{50} 51$ and is supported by educational research. ${ }^{52}$ While care must be undertaken to avoid the assumption that increased knowledge leads to increased reporting and safer behaviour, ${ }^{53}$ the provision of such education has been positively correlated with behaviour change. ${ }^{54}$ If this were to be combined with strategies that targeted attitudes and beliefs ${ }^{55}$ and self-efficacy (through increasing familiarity and challenging personal norms), it could lead to significantly improved practice within the amateur game. ${ }^{56}$

The self-reported nature of the study was one of its limitations and raises the possibility of various biases concerning recall and comparative optimism affecting the results. To limit the effect of these, it was made clear to participants that the responses were untraceable and certain questions involving personal practice were framed as neutral and as 'non-judgmental' as possible. ${ }^{57} 58$ As questionnaires were provided online, it raises the possibility of participants completing the survey while researching possible answers, but the fact that certain major misconceptions were present 
suggests otherwise. Also of concern was the relatively low response rate of coaches, ${ }^{35} 3759$ potentially demonstrating that the method of data collection was suboptimal and should be further developed for future studies among the same population. The lack of demographic data concerning non-respondents is also a limitation as it prohibits comparison between respondents and non-respondents, which could demonstrate any inherent biases affecting the results. Likewise, a different method of dissemination among coaches and referees along with the fact that the databases are controlled by different branches of the WRU means that there may be a difference in the representability of each cohort, which could limit the accuracy of any intergroup comparison. That the questionnaires are not validated limits generalisability. However, currently there is no comprehensive validated survey and the questionnaire, based on previously published versions, ${ }^{38}$ was refined by experienced sports medicine professionals and researchers and thoroughly piloted.

Future research should focus on the knowledge and attitudes of other groups involved in the amateur game such as players, medical providers and parents of youth level players, all of whom can play a key role in ensuring the optimal management of concussion across all levels of the sport. ${ }^{33} 3559-61$ The impact and use of any educational interventions should also be investigated alongside the role of confounding factors that influence the relationship between knowledge and application, in order to ensure that coaches, referees and all other relevant stakeholders are competent in recognising and managing this increasingly important sporting injury.

This study assessed the knowledge and experience of various aspects of concussion among coaches and referees involved in Welsh amateur rugby union. It identified a number of concussion-related misconceptions, especially in regard to prevention, clinical consequences and management, and emphasises an important need for further education via the preferred sources identified.

Acknowledgements The authors would like to acknowledge Mrs Claire Coleman and Mr Nigel Whitehouse of WRU for their assistance in contacting the study participants. The authors would also like to acknowledge Dr Rhodri Martin for his guidance and advice.

Contributors PM, CR and IM conceived the idea. SG analysed the data and drafted the initial paper. PM, CR and IM critically reviewed the initial draft. All were involved in arranging data collection along with further drafting and approval of the final manuscript.

Competing interests None declared.

Ethics approval Cardiff School of Sports Research Ethics Committee.

Provenance and peer review Not commissioned; externally peer reviewed.

Open Access This is an Open Access article distributed in accordance with the Creative Commons Attribution Non Commercial (CC BY-NC 4.0) license, which permits others to distribute, remix, adapt, build upon this work noncommercially, and license their derivative works on different terms, provided the original work is properly cited and the use is non-commercial. See: http:// creativecommons.org/licenses/by-nc/4.0/

(C) Article author(s) (or their employer(s) unless otherwise stated in the text of the article) 2017. All rights reserved. No commercial use is permitted unless otherwise expressly granted.

\section{REFERENCES}

1. Rugby W. Welcome to rugby: World Rugby. 2015 http://www. worldrugby.org/welcome-to-rugby

2. Gardner AJ, Iverson GL, Williams WH, et al. A systematic review and meta-analysis of concussion in rugby union. Sports Med 2014;44:1717-31.

3. Harmon KG, Drezner JA, Gammons M, et al. American Medical Society for Sports Medicine position statement: concussion in sport. Br J Sports Med 2013;47:15-26.

4. Chalmers DJ, Samaranayaka A, Gulliver P, et al. Risk factors for injury in rugby union football in New Zealand: a cohort study. $\mathrm{Br} J$ Sports Med 2012;46:95-102.

5. Kemp SP, Hudson Z, Brooks JH, et al. The epidemiology of head injuries in English professional rugby union. Clin J Sport Med 2008;18:227-34

6. Golding EM, Steenberg ML, Contant CF, et al. Cerebrovascular reactivity to $\mathrm{CO}(2)$ and hypotension after mild cortical impact injury. Am J Physiol 1999;277:H1457-66.

7. Schneiders AG, Takemura M, Wassinger CA. A prospective epidemiological study of injuries to New Zealand premier club rugby union players. Phys Ther Sport 2009;10:85-90.

8. Roberts SP, Trewartha G, England M, et al. Epidemiology of timeloss injuries in English community-level rugby union. BMJ Open 2013;3:e003998.

9. Moore IS, Ranson C, Mathema P. Injury risk in International Rugby Union: three-year injury surveillance of the Welsh National Team. Orthop J Sports Med 2015;3:2325967115596194.

10. Union RF. England Professional Rugby Injury Surveillance Project2013-2014 Season Report Rugby Football Union. 2015

11. Hootman JM, Dick R, Agel J. Epidemiology of collegiate injuries for 15 sports: summary and recommendations for injury prevention initiatives. J Athl Train 2007;42:311-9.

12. McCrea M, Hammeke T, Olsen G, et al. Unreported concussion in high school football players: implications for prevention. Clin J Sport Med 2004;14:13-17.

13. Williamson IJ, Goodman D. Converging evidence for the underreporting of concussions in youth ice hockey. Br J Sports Med 2006;40:128-32.

14. Chen JK, Johnston KM, Collie A, et al. A validation of the post concussion symptom scale in the assessment of complex concussion using cognitive testing and functional MRI. J Neurol Neurosurg Psychiatry 2007;78:1231-8.

15. Chen JK, Johnston KM, Frey S, et al. Functional abnormalities in symptomatic concussed athletes: an fMRI study. Neuroimage 2004;22:68-82.

16. Ptito A, Chen JK, Johnston KM. Contributions of functional magnetic resonance imaging (fMRI) to sport concussion evaluation. NeuroRehabilitation 2007;22:217-27.

17. McCrory P, Meeuwisse WH, Aubry M, et al. Consensus statement on concussion in sport: the 4th International Conference on Concussion in Sport held in Zurich, November 2012. Br J Sports Med 2013;47:250-8.

18. Marar M, Mcllvain NM, Fields SK, et al. Epidemiology of concussions among United States high school athletes in 20 sports. Am J Sports Med 2012;40:747-55.

19. McCrea M, Barr WB, Guskiewicz K, et al. Standard regressionbased methods for measuring recovery after sport-related concussion. J Int Neuropsychol Soc 2005;11:58-69.

20. Meehan WP. 3rd, d'Hemecourt P, Comstock RD. High school concussions in the 2008-2009 academic year: mechanism, symptoms, and management. Am J Sports Med 2010;38:2405-9.

21. Nordström A, Nordström P, Ekstrand J. Sports-related concussion increases the risk of subsequent injury by about $50 \%$ in elite male football players. Br J Sports Med 2014;48:1447-50.

22. Williams S, Trewartha G, Kemp SP, et al. Time loss injuries compromise team success in Elite Rugby Union: a 7-year prospective study. Br J Sports Med 2016;50:651-6.

23. Cross M, Kemp S, Smith A, et al. Professional Rugby Union players have a $60 \%$ greater risk of time loss injury after concussion: a 2season prospective study of clinical outcomes. Br J Sports Med 2016;50:926-31. 
24. Guskiewicz KM, Marshall SW, Bailes J, et al. Recurrent concussion and risk of depression in retired professional football players. Med Sci Sports Exerc 2007;39:903-9.

25. Guskiewicz KM, Marshall SW, Bailes J, et al. Association between recurrent concussion and late-life cognitive impairment in retired professional football players. Neurosurgery 2005;57:719-26.

26. Raftery M, Kemp S, Patricios J, et al. It is time to give concussion an operational definition: a 3-step process to diagnose (or rule out) concussion within $48 \mathrm{~h}$ of injury: World Rugby guideline. $\mathrm{Br} J$ Sports Med 2016;50:642-3.

27. Union WR. Concussion. 2015 www.wru.co.uk/medical

28. Baker JF, Devitt BM, Green J, et al. Concussion among under 20 rugby union players in Ireland: incidence, attitudes and knowledge. Ir J Med Sci 2013;182:121-5.

29. Fraas MR, Coughlan GF, Hart EC, et al. Concussion knowledge and management practices among coaches and medical staff in Irish professional rugby teams. Ir J Med Sci 2015;184:425-30.

30. Fraas MR, Coughlan GF, Hart EC, et al. Concussion history and reporting rates in elite Irish rugby union players. Phys Ther Sport 2014;15:136-42.

31. King DA HP, Clark T. First aid and concussion knowledge of rugby league team management, administrators, and officials in New Zealand. New Zeal J Sport Med 2010;37:16.

32. Lin AC, Salzman GA, Bachman SL, et al. Assessment of parental knowledge and attitudes toward pediatric sports-related concussions. Sports Health 2015;7:124-9.

33. Sye G, Sullivan SJ, McCrory P. High school rugby players' understanding of concussion and return to play guidelines. $\mathrm{Br} \mathrm{J}$ Sports Med 2006;40:1003-5.

34. Sullivan SJ, Bourne L, Choie S, et al. Understanding of sport concussion by the parents of young rugby players: a pilot study. Clin $J$ Sport Med 2009;19:228-30.

35. Broglio SP, Vagnozzi R, Sabin M, et al. Concussion occurrence and knowledge in italian football (soccer). J Sports Sci Med 2010;9:418-30.

36. O'Donoghue EM OJ, Van Lunen B, et al. Assessment of high school coaches' knowledge of sport-related concussions. Athl Train Sport Heal Care J Pract Clin 2009;1:12.

37. Valovich McLeod TC, Schwartz C, Bay RC. Sport-related concussion misunderstandings among youth coaches. Clin J Sport Med 2007;17:140-2

38. Mathema P, Evans D, Moore IS, et al. Concussed or not? An assessment of concussion experience and knowledge within elite and semiprofessional rugby union. Clin J Sport Med 2016;26:320-5.

39. White PE, Newton JD, Makdissi M, et al. Knowledge about sportsrelated concussion: is the message getting through to coaches and trainers? Br J Sports Med 2014;48:119-24.

40. The referee's power to stop an injured player from continuing 3.9. 2015.

41. Rugby W. World Rugby Concussion Management. 2015 http:// playerwelfare.worldrugby.org/concussion

42. Marshall SW, Loomis DP, Waller AE, et al. Evaluation of protective equipment for prevention of injuries in rugby union. Int J Epidemiol 2005;34:113-8.
43. Mclntosh AS, McCrory P. Effectiveness of headgear in a pilot study of under 15 rugby union football. Br J Sports Med 2001;35:167-9.

44. Mclntosh AS, McCrory P, Finch CF, et al. Does padded headgear prevent head injury in rugby union football? Med Sci Sports Exerc 2009;41:306-13.

45. Holbrook A. Self-reported measure. Encyclopedia of survey research methods 2008:805-7.

46. Dispositional RNMKW. Unrealistic and comparative optimism: differential relations with the knowledge and processing of risk information and beliefs about personal risk. Pers Soc Psychol Bull 2002;28:10.

47. Donaldson SI G-VE. Understanding self-report bias in organizational behavior research. J Bus Psychol 2002;15.

48. Kirkwood MW, Yeates KO, Wilson PE. Pediatric sport-related concussion: a review of the clinical management of an oft-neglected population. Pediatrics 2006;117:1359-71.

49. Union WR. WRU launches nationwide concussion education programme. 2015 http://www.wru.co.uk/eng/news/31229.php\#.VR5 EBvnF8rU

50. Covassin T, Elbin RJ, Sarmiento K. Educating coaches about concussion in sports: evaluation of the CDC's "Heads Up: concussion in youth sports" initiative. J Sch Health 2012;82:233-8.

51. Sarmiento K, Mitchko J, Klein C, et al. Evaluation of the Centers fo Disease Control and Prevention's concussion initiative for high school coaches: "Heads Up: Concussion in High School Sports". $J$ Sch Health 2010;80:112-8.

52. Mrazik M, Dennison CR, Brooks BL, et al. A qualitative review of sports concussion education: prime time for evidence-based knowledge translation. Br J Sports Med 2015;49:1548-53.

53. Register-Mihalik JK, Guskiewicz KM, McLeod TC, et al. Knowledge, attitude, and concussion-reporting behaviors among high school athletes: a preliminary study. J Athl Train 2013;48:645-53.

54. Brown J, Lubbe S, Lambert M, et al. The effectiveness of the boksmart intervention: the association between knowledge, education and perceptions and injury prevention behaviour in rugby union players. Br J Sports Med 2014;48:575.1-575.

55. Kroshus $\mathrm{E}$, Baugh $\mathrm{CM}$, Hawrilenko MJ, et al. Determinants of coach communication about concussion safety in US collegiate sport. Ann Behav Med 2015;49:532-41.

56. Newton JD, White PE, Ewing MT, et al. Intention to use sport concussion guidelines among community-level coaches and sports trainers. J Sci Med Sport 2014;17:469-73.

57. Nf PC. Medicines Adherence: Royal College of General Practitioners. 2015 http://www.ncbi.nlm.nih.gov/books/PMH0015337/

58. Lelkes YKJ, Marx DM, et al. Complete anonymity compromises the accuracy of self-reports. J Exp Soc Psychol 2012;48:8.

59. Guilmette TJ, Malia LA, McQuiggan MD. Concussion understanding and management among New England high school football coaches. Brain Inj 2007;21:1039-47.

60. Bramley H, Patrick K, Lehman E, et al. High school soccer players with concussion education are more likely to notify their coach of a suspected concussion. Clin Pediatr 2012;51:332-6.

61. Mrazik M, Bawani F, Krol AL. Sport-related concussions: knowledge translation among minor hockey coaches. Clin J Sport Med 2011;21:315-9. 